\title{
O DIREITO FUNDAMENTAL DE TESTAR
}

\section{Raphael Rego Borges Ribeiro*}

\section{Resumo:}

Neste artigo, defendemos a existência de um direito fundamental de fazer testamento. Usamos a metodologia civil-constitucional e adotamos a doutrina de Robert Alexy como marco teórico. Partindo da premissa da dupla titularidade do direito à herança, deduzimos que o direito de testar está incluído no âmbito de proteção do artigo $5^{\circ}, \mathrm{XXX}$ da Constituição Federal. Depreendemos que a abolição da sucessão testamentária é vedada, tanto por lei ordinária como por emenda constitucional. Concluímos ainda que o direito de testar não é absoluto, podendo sofrer restrições quantitativas e qualitativas justificadas por outros valores constitucionalmente tutelados.

Palavras-chave: Direitos fundamentais; Herança; Testamento; Sucessão Testamentária; Direito das Sucessões.

\section{THE FUNDAMENTAL RIGHT TO WRITE A WILL}

Abstract: In this paper, I argued that there is a fundamental right to write a will. I used the civil-constitutional methodology and adopted Robert Alexy's theory as a framework. Considering the ambivalent character of inheritance, I inferred that testamentary freedom stems from the Federal Constitution art. 5, XXX. I argued that the abolishment of testamentary succession is not legally possible, not even through a constitutional amendment. I concluded that testamentary freedom is not an unlimited right, being subject to restrictions derived from other constitutionally protected values.

Keywords: Fundamental rights; Inheritance; Will; Testamentary Succession; Inheritance Law.

\section{INTRODUÇÃO}

A presente investigação parte de um singelo questionamento: se o legislador decidisse vedar absolutamente a sucessão testamentária, impondo que toda a distribuição da herança necessariamente seguisse as normas da sucessão intestada, tal alteração legislativa seria constitucional? Digamos que a motivação do legislador, nesse caso, seja a melhor possível, partindo de uma compreensão de que o testamento é uma expressão de acentuado

\footnotetext{
* Bacharel, Mestre e Doutor em Direito pela Universidade Federal da Bahia. Graduate student e pesquisador no Health Law Centre da University of Ottawa. Professor de Direito Civil da Universidade Federal do Oeste da Bahia.
} 
individualismo, o que supostamente seria incompatível com o paradigma de solidariedade constitucional; ou ainda que politicamente se decida não ser mais conveniente dar eficácia a negócios jurídicos causa mortis. Em qualquer caso, entendemos que não é possível abolir a sucessão testamentária no Brasil, na medida em que violaria o direito fundamental de fazer testamento, implicitamente tutelado pela Constituição Federal de 1988 (e, consequentemente, oponível contra o legislador ordinário e amparado pela intangibilidade das cláusulas pétreas).

A discussão sobre o fundamento do direito de testar não é recente, podendo inclusive ser encontrada na obra de filósofos da Antiguidade greco-romana (MIRAGLIA, 1943, p.555). Acreditamos, porém, que a concepção moderna sobre a natureza do testamento ganhou os atuais contornos a partir dos debates sobre o tema no movimento jusracionalista europeu dos séculos XVII e XVIII ${ }^{1}$. De um lado, tínhamos Hugo Grotius (2012, p.143) e seus seguidores considerando que a sucessão testamentária decorre naturalmente do direito de propriedade e, assim, tem seu fundamento no Direito Natural. Por outro lado, tínhamos Samuel Pufendorf (1703, p.369) e seus discípulos negando que a livre disposição post mortem seja inerente à propriedade e compreendendo assim o testamento como meramente fundamentado em leis humanas (e suscetível, portanto, de abolição pelas legislações) ${ }^{2}$.

$\mathrm{Na}$ presente investigação, utilizaremos a metodologia civil-constitucional, em especial no que diz respeito à eficácia das normas da Constituição sobre a estrutura e a função dos institutos clássicos do Direito Privado. Testaremos a hipótese da existência de um direito fundamental de testar utilizando o método indutivo-dedutivo, aplicando as premissas da teoria geral dos direitos fundamentais ao direito de herança. Adotaremos especialmente como referencial teórico e premissa das nossas deduções a doutrina do autor germânico Robert Alexy.

A justificativa remota para a presente investigação é uma premissa política muito simples: o Brasil necessita de mais pesquisas em Direito das Sucessões - em especial para que este ramo deixe de ser institucionalmente tratado como mero apêndice do Direito das Famílias. Por outro lado, a justificativa imediata para o presente artigo é o fato de notarmos que, apesar da constitucionalização expressa da herança, a doutrina civilista pouco tem se

1 Para um maior aprofundamento no estudo da Escola Jusracionalista Moderna, recomendamos a leitura de Franz Wieacker (1967, p.280).

2 Para um maior aprofundamento no debate sobre o pertencimento do testamento ao Direito Natural, recomendamos o artigo Hugo Grotius and Samuel Pufendorf on Last Wills and Testaments, referenciado ao final (RIBEIRO, 2019). 
debruçado sobre a aplicação da teoria dos direitos fundamentais ao Direito das Sucessões deixando um gap acadêmico que ora tentamos contribuir para que seja preenchido. ${ }^{3}$ Por fim, não se trata de temática inócua e sem aplicação prática; por exemplo, a Suprema Corte dos Estados Unidos já decidiu que, lá, não há um direito de testar constitucionalmente protegido ${ }^{4}$ (o que particularmente imputamos à influência da obra de Samuel Pufendorf no pensamento de Thomas Jefferson).

O primeiro objetivo desse trabalho é averiguar se, e de que modo, do direito fundamental à herança decorre a existência de um direito fundamental de fazer testamento. $\mathrm{O}$ segundo objetivo é analisar se apenas a sucessão legítima é abarcada pela proteção constitucional à herança. $\mathrm{O}$ terceiro objetivo é compreender as consequências de a liberdade de testar ser reconhecida como fundamental.

\section{O DIREITO FUNDAMENTAL DE TESTAR COMO DESDOBRAMENTO DA DIMENSÃO SUBJETIVA DO DIREITO FUNDAMENTAL À HERANÇA}

Se procurarmos no rol dos direitos e garantias individuais da Constituição, não encontraremos ali um dispositivo expressamente tutelando o direito de testar. Uma postura simplista seria considerar natimorta nossa hipótese de trabalho. Contudo, a ausência de previsão expressa do direito fundamental a fazer testamento não é um impeditivo para nossa análise, uma vez que o próprio texto constitucional admite a existência de direitos fundamentais implícitos, decorrentes do regime e dos princípios por ela adotados ${ }^{5}$.

$\mathrm{Na}$ doutrina brasileira, normalmente encontramos reflexões imputando o fundamento do direito de testar como decorrência da propriedade, da vontade ou até mesmo da personalidade do testador ${ }^{6}$. Não negamos a íntima relação entre o direito de testar e a liberdade, a propriedade e a autonomia privada (em suas dimensões patrimonial e existencial).

3 Questionamo-nos se e, em caso positivo, até que ponto causou estranheza Robert Alexy ser o referencial teórico de um artigo dirigido a um Grupo de Trabalho em Direito das Famílias e das Sucessões.

4 Irving Trust Co. v. Day, 314 US 556, 562 (1942). Ver também: Demorest v. City Bank Farmers Trust Co., Trust Co., 321 US 36, 48 (1944).

5 Constituição Federal de 1988, art. $5^{\circ}, \S 2^{\circ}$ Os direitos e garantias expressos nesta Constituição não excluem outros decorrentes do regime e dos princípios por ela adotados, ou dos tratados internacionais em que a República Federativa do Brasil seja parte.

6 A título ilustrativo, Itabaiana de Olveira (1936, p.46); Carlos Maximiliano (1964, p.338); Zeno Veloso (2004, p.123); Eduardo de Oliveira Leite (2003, p.302); Pontes de Miranda (2005, p.36). 
Entendemos, porém, que a faculdade de testar é fundamental notadamente porque se trata de um desdobramento inexorável da perspectiva subjetiva do direito fundamental à herança que, por sua vez, foi elevado expressamente pela Constituição Federal de 1988 ao patamar de fundamentalidade no seu artigo $5^{\circ}, \mathrm{XXX}$.

Para demonstrarmos as bases dessa conclusão, precisamos enfrentar três temáticas à luz da teoria dos direitos fundamentais: em primeiro lugar, a tese da dupla titularidade do direito fundamental à herança; em segundo lugar, a dimensão subjetiva do direito fundamental à herança enquanto uma liberdade jurídica; em terceiro lugar, a dimensão subjetiva do direito fundamental à herança enquanto uma competência. Por fim, desconstruiremos o entendimento de que apenas a sucessão legítima é tutelada pela Constituição Federal.

\subsection{A DUPLA TITULARIDADE DO DIREITO FUNDAMENTAL À HERANÇA}

A primeira premissa da qual partimos para encontrar um direito fundamental de testar consiste na tese da dupla titularidade do direito fundamental à herança. Isso que significa que consideramos que o artigo $5^{\circ}, \mathrm{XXX}$ da Constituição é titularizado por dois sujeitos distintos: em primeiro lugar, aquele que deixa a herança, o sucedido; em segundo lugar, aquele que recebe a herança, o sucessor.

Reconhecemos que não se trata de tese aceita unanimemente na doutrina. Em sua instigante tese de doutoramento defendida junto ao Programa de Pós-Graduação em Direito da Universidade Federal do Ceará, Felipe Lima Gomes (2015, p.76) rejeitou o caráter ambivalente do direito à herança. Argumentou primeiramente que a existência da sucessão forçada (a legítima dos herdeiros necessários) é logicamente incompatível com a titularidade do direito à herança por parte do de cujus. Em segundo lugar, sustentou que a disposição mortis causa do patrimônio se encontra no conteúdo do direito de propriedade do sucedido, não no do direito à herança. Por fim, induziu que, na medida em que (alegadamente) só existe herança a partir da abertura da sucessão, o de cujus não pode ter direito à herança uma vez que com a morte sua personalidade (e portanto status quo de sujeito de direito) se extingue (GOMES, 2015, p.93). Discordamos frontalmente de todos os argumentos suscitados. 
Em primeiro lugar, não acreditamos que a sucessão forçada seja incompatível com um direito à herança titularizado pelo sucedido. A teoria das restrições ao âmbito de proteção dos direitos fundamentais é amplamente reconhecida, além de que não faria qualquer sentido alegar que a herança seria um direito absoluto, não passível de ser restringido; sobre o assunto traçaremos algumas reflexões na seção 3. Desse modo, compreendemos que a legítima se trata justamente de um limite ao direito fundamental à herança do de cujus - por sinal, um limite constitucionalmente justificado, à luz da proteção patrimonial a determinadas pessoas próximas ao falecido.

Em segundo lugar, entendemos que, embora o conteúdo do direito de propriedade envolva a faculdade de dispor, isso por si só não significa que o poder de disposição seja necessariamente tanto inter vivos quanto causa mortis. Ilustrativamente, o titular de uma propriedade resolúvel, que se resolverá com o seu falecimento, não deixa de ser proprietário, enquanto viver, por não ter poder de disposição sobre o referido bem para além da sua morte. Além disso, ao contrário do quanto equivocadamente suscitado em muitos manuais de graduação, se o legislador pudesse abolir totalmente a herança, a impossibilidade de transmitir causa mortis os seus bens não transformaria os proprietários em meros usufrutuários: propriedade é direito real na coisa própria, usufruto é direito real na coisa alheia; além disso, enquanto o proprietário poderá continuar alienando seus bens entre vivos, o usufrutuário não tem poder de disposição sobre a coisa que não é sua, além de não poder sequer alienar o próprio usufruto $^{7}$. Desse modo, acreditamos, assim como Mark Ascher (1990, p.83), que a transmissão causa mortis não é um componente teoricamente imprescindível da propriedade. Por essa razão, compreendemos que a transmissão patrimonial causa mortis requer fundamento próprio, para além dos poderes inerentes ao domínio, apenas; e esse fundamento é justamente o reconhecimento de que o sucedido tem direito a transmitir herança.

Em terceiro lugar, discordamos da premissa de que o direito à herança não pode ser titularizado pelo de cujus em razão de apenas passar a existir quando a personalidade deste é extinta. Não negamos a óbvia relevância do fato jurídico morte para o fenômeno sucessório; entretanto, defendemos que o direito à herança já é juridicamente relevante mesmo enquanto

7 Código Civil de 2002, Art. 1.394. O usufrutuário tem direito à posse, uso, administração e percepção dos frutos. Art. 1.393. Não se pode transferir o usufruto por alienação; mas o seu exercício pode ceder-se por título gratuito ou oneroso. 
o futuro de cujus ainda é vivo. Identificamos no artigo 549 do Código Civil de $2002^{8}$ um claro exemplo de que, mesmo antes da abertura da sucessão, o potencial e ainda não adquirido direito à herança, titularizado pelo futuro sucessor, limita para o futuro sucedido o conteúdo do seu direito de propriedade - no caso, o poder de disposição patrimonial gratuita inter vivos. Do mesmo modo, o potencial interesse sucessório sobre determinados bens consiste em um dos fundamentos da exigência de outorga conjugal para a prática de certos atos ${ }^{9}$. Parece-nos evidente que os interesses do potencial sucessor relativos à herança já são juridicamente tutelados pelo ordenamento antes mesmo da abertura da sucessão; a decorrência lógica é que absolutamente nada impede que, do mesmo modo, o ordenamento tutele os interesses de alguém, ainda vivo, em relação à sua própria sucessão.

Após analisar a estrutura sucessória dos Estados Unidos, dos demais países cujo regime jurídico é o common law, bem como dos países que aderem ao civil law, Shelly Kreiczer-Levy $\left(2012\right.$, p.497) concluiu que nos três ${ }^{10}$ sistemas a herança é bifocal, no sentido de servir aos interesses tanto de quem a transmite quanto de quem a recebe. Para ela, uma visão holística da herança requer que combinemos os interesses do de cujus e dos beneficiários, posição à qual nos filiamos.

Com base no mencionado estudo de Shelly Kreiczer-Levy, aderimos também à doutrina de Liam Murphy e Thomas Nagel (2003, p.161), segundo quem a sucessão causa mortis necessariamente envolve duas partes, que devem ser distinguidas e tratadas separadamente: o direito de transmitir a herança; e o direito de receber a herança.

Conclusivamente, assentamos a nossa primeira premissa: o artigo $5^{\circ}, \mathrm{XXX}$ da Constituição Federal de 1988 tutela, a nível individual, interesses jurídicos tanto daquele que receberá a herança (o sucessor), quanto daquele que a transmitirá (o sucedido). Havendo uma

8 Art. 549. Nula é também a doação quanto à parte que exceder à de que o doador, no momento da liberalidade, poderia dispor em testamento.

9 Art. 1.647. Ressalvado o disposto no art. 1.648, nenhum dos cônjuges pode, sem autorização do outro, exceto no regime da separação absoluta: I - alienar ou gravar de ônus real os bens imóveis.

10 Aqui devemos fazer uma importante ressalva. Falamos em três sistemas porque, além do civil law e da common law, em matéria hereditária, devemos tratar separadamente os Estados Unidos em relação às demais jurisdições de common law. O regime sucessório norte-americano de modo geral direciona excessivo foco na noção de propriedade e da necessidade de organização de sua transferência após a morte do indivíduo. Mais preocupado com a noção de controle da propriedade durante a vida e para além da morte, trata-se de um sistema cujo princípio norteador é a autonomia, refletida na liberdade testamentária (TRITT, 2010, p.280). Ali, as noções de solidariedade familiar são muito mais tímidas do que, de modo geral, no resto do mundo ocidental, inclusive no Brasil. Até mesmo as demais jurisdições de common law abrandaram os rigores da excessiva liberdade testamentária, com a adoção do instituto da family provision,. 
dupla ordem de titulares, portanto, o direito fundamental à herança é ambivalente, ou seja, tem uma dupla titularidade. Encontramos o direito fundamental de testar no âmbito de proteção do direito subjetivo à herança titularizado pelo sucedido.

\subsection{A DIMENSÃO SUBJETIVA DO DIREITO FUNDAMENTAL À HERANÇA}

Os direitos fundamentais como um todo têm dupla perspectiva: são, ao mesmo tempo, direitos subjetivos individuais (dimensão subjetiva) e elementos objetivos fundamentais da sociedade (dimensão objetiva) ${ }^{11}$. Para os fins desta pesquisa, restringir-nos-emos por ora à perspectiva subjetiva dos direitos fundamentais no sentido de estes serem entendidos, ressalvadas suas peculiaridades ${ }^{12}$, como direitos subjetivos. José Carlos Vieira de Andrade (2001, p.115) identifica dois aspectos na perspectiva subjetiva dos direitos fundamentais. Por um lado, o aspecto funcional refere-se ao reconhecimento da existência (e consequente busca de satisfação) de interesses próprios dos titulares. Ao mesmo tempo, o aspecto estrutural diz respeito à proteção intencional e efetiva desses interesses, proteção esta à qual corresponde o "poder de exigir ou de pretender comportamentos (positivos ou negativos) ou de produzir autonomamente efeitos jurídicos".

Robert Alexy (2015, p.193) propõe a tríplice divisão dos direitos fundamentais (“posições jurídicas fundamentais"), em sua perspectiva subjetiva, em "direitos a algo", "liberdades" e "competências". Na esteira da referida classificação, para fundamentarmos a existência de um direito fundamental de testar, analisaremos o direito à herança especificamente enquanto uma "liberdade" e uma "competência".

11 A este respeito, mencionamos Daniel Sarmento (2008 p.105), que sucintamente afirma: "Deveras, os direitos fundamentais no constitucionalismo liberal eram visualizados exclusivamente a partir de uma perspectiva subjetiva, pois cuidava-se apenas de identificar quais pretensões o indivíduo poderia exigir do Estado em razão de um direito positivado na sua ordem jurídica. Sem desprezar este papel dos direitos fundamentais, que não perdeu a sua essencialidade na teoria contemporânea, a doutrina vai agora desvelar uma outra faceta de tais direitos, que virá para agregar-lhes novos efeitos e virtualidades: trata-se da chamada dimensão objetiva dos direitos fundamentais. A dimensão objetiva dos direitos fundamentais liga-se ao reconhecimento de que tais direitos, além de imporem certas prestações aos poderes estatais, consagram também os valores mais importantes em uma comunidade política".

12 As peculiaridades dos direitos fundamentais se referem à qualidade dos sujeitos passivos típicos, à multiplicidade de conteúdos, à variedade e complexidade estrutural, à diversidade funcional e à sujeição a diferentes regimes constitucionais; tudo isso os diferencia da generalidade dos direitos subjetivos típicos do Direito Privado (ANDRADE, 2001, p.116). 


\subsubsection{O direito fundamental à herança enquanto uma liberdade}

No contexto da perspectiva subjetiva dos direitos fundamentais, seguindo a doutrina de Robert Alexy (2015, p.218), utilizaremos a palavra "liberdade" na acepção de liberdade jurídica. A base do conceito de liberdade é constituída "por uma relação triádica entre um titular de uma liberdade (ou de uma não-liberdade), um obstáculo à liberdade e um objeto da liberdade" (ALEXY, 2015, p.220). De acordo com Alexy (2015, p.222), somente podemos falar em liberdade jurídica quando o objeto desta for uma alternativa de ação; o conceito não se refere ao que o titular deve fazer ou irá fazer, mas sobre as suas possibilidades de fazer (e, semelhantemente, de não fazer) algo. Assim, por exemplo, quando nos referimos à liberdade (jurídica) de expressão, estamos tratando da permissão jurídica para que o titular expresse a sua opinião, bem como para que ele deixe de fazê-lo (ALEXY, 2015, p.226). Porém, para Alexy (2015, p.227), a simples permissão do fazer (ou não fazer) algo constitui, por si só, uma liberdade não-protegida. Uma liberdade somente poderá ser considerada protegida quando for "constituída por um feixe de direitos a algo e também por normas objetivas que garantem ao titular do direito fundamental a possibilidade de realizar a ação permitida" (ALEXY, 2015, p.233).

Na doutrina de Robert Alexy (2015, p.234), a liberdade pode ser protegida em face do Estado tanto negativamente quanto positivamente. No primeiro caso, a proteção se dá pelo direito ao não-embaraço de ações, ao qual correspondem proibições de ações que embaracem as liberdades fundamentais. Por outro lado, a proteção é positiva quando se combina a liberdade com o direito a uma ação positiva, no sentido de se "tornar faticamente possível ao portador da liberdade aquilo que a ele é permitido e, nesse sentido, juridicamente possível” (ALEXY, 2015, p.234).

Partindo da premissa da tese da dupla titularidade do direito fundamental à herança, e pensando no seu âmbito de proteção no que diz respeito à figura do sucedido, é fácil verificar tal direito enquanto uma liberdade jurídica no sentido empregado por Robert Alexy, ou seja, uma alternativa de ação. O direito de testar decorre do se observar o direito à herança enquanto uma liberdade reconhecida ao potencial sucedido. Ao sujeito é dada a possibilidade de fazer testamento, negócio jurídico em que pode manifestar aquela que será considerada a 
sua última vontade - notadamente, mas não exclusivamente, no sentido determinar como se dará a transmissão post mortem do seu patrimônio. Obviamente, também é dada ao sujeito a possibilidade de não fazer testamento; a priori não existe dever jurídico de testar. Ademais, a liberdade de testar não é uma simples permissão; trata-se de uma liberdade protegida, no supramencionado sentido que Alexy dá à expressão. A ação permitida (elaborar um testamento) é regulamentada por diversas normas de direito objetivo que garantem o ato de disposição por parte do testador - em especial, todo o Título III do Livro V da Parte Especial do Código Civil de 2002.

Resumidamente, compreendemos que no âmbito de proteção do direito fundamental à herança, quando se considera o sucedido, está a alternativa de ação, ou seja, a faculdade de fazer testamento. Nesse sentido, então, a liberdade fundamental de testar deve ser protegida tanto negativamente quanto positivamente.

Em primeiro lugar, a proteção desse direito se dá de forma negativa pela ideia de não-embaraço de ações: a ninguém - seja particular ou seja o Estado - é dado o direito de impedir que uma pessoa teste, salvo por razões constitucionalmente justificadas. Assim, se o Estado arbitrariamente proibir seus cidadãos de fazer testamento, tal vedação seria um embaraço inconstitucional por violação do direito de herança enquanto liberdade. Acreditamos que um exemplo de razão constitucionalmente justificada para ao embaraço ao exercício da liberdade de testar é a exigência de capacidade civil específica para a prática do ato. Por um outro lado, vemos um exemplo da proteção negativa positivada no artigo 1.814 , III do Código Civil de $2002^{13}$, que prevê a exclusão por indignidade daquele que tenha atentado contra a liberdade de testar do de cujus. Obviamente, o não-embaraço à ação de testar não significa que se trata de uma liberdade ilimitada; assim, ao regulamentar juridicamente o ato de disposição, o Estado lhe imporá determinadas restrições - tanto em relação ao conteúdo quanto à forma.

Em segundo lugar, em relação à proteção positiva da herança enquanto uma liberdade fundamental titularizada pelo sucedido, compreendemos que daí decorre a necessidade de se assegurarem as possibilidades, tanto jurídicas quanto materiais, para que alguém faça testamento. Consequentemente, se o legislador decidisse pela abolição da

13 Art. 1.814. São excluídos da sucessão os herdeiros ou legatários: (...) III - que, por violência ou meios fraudulentos, inibirem ou obstarem o autor da herança de dispor livremente de seus bens por ato de última vontade. 
sucessão testamentária e pela revogação das normas que a regulamentam, estaria eliminando a possibilidade jurídica de testar - o que, acreditamos, consistiria em uma violação ao âmbito de proteção do artigo $5^{\circ}$, XXX da Constituição Federal.

Por outro lado, ainda tratando do tema da proteção positiva do direito fundamental à herança, em relação às possibilidades materiais de se testar, entendemos que há um imperativo constitucional direcionado ao legislador, consistente no seguinte mandamento: facilite o ato de testar, torne mais acessível a liberdade de fazer testamento. Identificamos na redução das solenidades testamentárias no Código de 2002 em relação ao de 1916 uma tentativa de cumprimento desse mandamento constitucional. Do mesmo modo, consideramos um avanço nesse sentido a inovação legislativa do artigo 1.879, que introduziu no Brasil o testamento hológrafo simplificado, feito de próprio punho sem a necessidade de testemunhas, desde que em circunstâncias excepcionais declaradas na cédula - por sinal, tema muito relevante em tempos de pandemia do COVID-19. Apesar dos mencionados avanços, defendemos que o Código Civil de 2002 foi muito tímido nas alterações e permaneceu muito aquém do que deveria no sentido de democratizar o acesso ao testamento - a legislação continua excessivamente apegada a formalidades e se manteve fechada a novas tecnologias, para além da folha de papel, como o testamento eletrônico ou feito com recursos audiovisuais. $\mathrm{Na}$ medida em que o tema requer investigação própria, não nos aprofundaremos no referido debate, deixando apenas a crítica e o convite à reflexão.

\subsubsection{O direito fundamental à herança enquanto uma competência}

Os direitos fundamentais, em sua perspectiva subjetiva, podem se apresentar como competências, sejam do cidadão, sejam do Estado. Em relação aos indivíduos, as "competências" constituem um terceiro grupo de posições jurídicas fundamentais ao lado dos "direitos a algo" e das "liberdades". De acordo com Robert Alexy (2015, p.236), "por meio de determinadas ações do titular ou dos titulares da competência, uma situação jurídica é alterada", seja pela criação de normas (tanto individuais quanto gerais) ou pela alteração das posições jurídicas daqueles indivíduos submetidos às normas. 
A alteração de situação jurídica é essencial à noção de competência. Com base nessa premissa, Robert Alexy (2015, p.237) estabelece a distinção entre os conceitos de competência e de permissão: "uma ação que seja meramente a realização de algo permitido não é, por si só, o exercício de uma competência, o que é perceptível pela diversidade de ações permitidas que não implicam alteração de uma situação jurídica”. Apesar disso, a alteração da situação jurídica, por si só, não é um critério adequado para distinguir competência de capacidade fática. Atos delituosos modificam situações jurídicas sem, no entanto, que sua prática seja considerada como exercício de competência (ALEXY, 2015, p.238). Dessa forma, para Alexy (2015, p.239), o exercício de uma competência se dá por meio de ações institucionais, isto é, "ações que podem ser realizadas não somente em razão de capacidades naturais; elas pressupõem a existência de regras que lhes são constitutivas”. Essa natureza constitutiva das normas de competência serve de parâmetro diferenciador em relação às normas de conduta, pois estas últimas simplesmente qualificam ações, estabelecendo obrigações, direitos a algo e liberdades (ALEXY, 2015, p.240). Nesse contexto, é essencial que compreendamos que os institutos jurídicos de Direito Privado (como, por exemplo, o casamento e a propriedade) são "complexos de normas formados essencialmente por normas de competência" (ALEXY, 2015, p.245).

Existe uma relação entre liberdades e competências: a atribuição de competências a alguém cria novas (e, portanto, aumenta o número de) alternativas de ação disponíveis a esse sujeito. Na medida em que um indivíduo só é juridicamente livre para realizar um ato jurídico quando há uma norma que lhe atribua a competência para o fazer, "o não-reconhecimento ou a eliminação de uma competência é um obstáculo para a liberdade - e, sem dúvida, um obstáculo especialmente eficaz"(ALEXY, 2015, p.246).

Um claro exemplo em que vemos o direito fundamental à herança enquanto uma competência é, do ponto de vista do sucedido, a competência para fazer testamento. O testador altera a situação jurídica dos sucessores, em especial modificando, dentro de certos limites, o esquema legal de distribuição do patrimônio hereditário. Assim, para ficar nos exemplos mais comuns, ele tem a liberdade de chamar quem originalmente não seria chamado, ou de aumentar o quinhão de alguém que originalmente receberia menos. $\mathrm{O}$ ato de testar é uma competência porque se dá por meio de ações institucionais, na medida em que pressupõe regras que lhe regulamentem e deem eficácia jurídica às disposições testamentárias. 
Ainda de acordo com Robert Alexy (2015, p.244), há competências que gozam da qualidade de direitos fundamentais (e, portanto, da proteção daí advinda), como aquelas relacionadas aos institutos jurídicos de Direito Privado, por exemplo, a competência para se casar, para constituir associação, para adquirir propriedade ou para testar. Existe, assim, uma proteção contra a ação do legislador, direcionada à eliminação ou à alteração substancial desses institutos jurídicos de Direito Privado. Essa proibição de eliminação das competências relacionadas aos institutos jurídicos de Direito Privado consubstancia o núcleo da chamada "teoria da garantia de institutos"14. Nessa perspectiva, as competências para adquirir herança e para testar, por exemplo, são protegidas contra a ações legislativas tendentes a as eliminar.

Por fim, em relação à competência do Estado, as normas de direito fundamental, em perspectiva subjetiva, atuam como normas negativas de competência (ALEXY, 2015, p.247). Elas conferem ao indivíduo um âmbito de não-sujeição ao Estado, dentro do qual o Estado não tem competência para agir. De acordo com Ingo Wolfgang Sarlet (2015, p.151), o Estado, poder constituído que é, só pode agir dentro dos limites que lhe foram determinados pelo poder constituinte. Os direitos fundamentais, em sentido subjetivo, consubstanciam uma dessas limitações, retirando do espaço de atuação estatal certos interesses constitucionalmente considerados dignos de tutela e proteção. Com base nessa perspectiva, consideramos que, ao vedar em regra a disposição testamentária em favor do concubino, o Estado ultrapassa os seus limites de atuação, violando tanto a liberdade de testar do sucedido casado quanto o direito a ser sucessor por parte do seu concubino ${ }^{15}$.

Conclusivamente, identificamos assim a competência para fazer testamento no âmbito de proteção do direito fundamental à herança do ponto de vista do sucedido: o testador altera a situação jurídica dos sucessores, em especial modificando, dentro de certos limites, o esquema legal de distribuição do patrimônio hereditário. Sustentamos, por fim, que, conforme a "teoria da garantia dos institutos", existe uma proteção contra a ação do legislador direcionada à eliminação ou à alteração substancial desses institutos jurídicos de Direito Privado que configuram direitos fundamentais a competências. Nessa perspectiva, a competência para testar é protegida contra a ações legislativas tendentes a aboli-la.

14 Concebida por Martin Wolff, em seu Reichsverfassung und Eigentum, e aperfeiçoada por Carl Schmitt, em seu Freiheitsrechte und institutionelle Garantien der Reichsverfassung.

15 Art.1.801, III do Código Civil de 2002. Ressalvamos que o tópico requer estudo aprofundado em momento próprio, na medida em que envolve diversos outros interesses jurídicos relevantes. 


\subsection{NÃO APENAS A SUCESSÃO LEGÍTIMA É PROTEGIDA PELO ART. 5º XXX}

Por fim, devemos enfrentar ainda o entendimento de Paulo Lôbo (2014, p.39-41; 2017, p.147-149) que, por um lado, entende que o artigo 5, XXX da Constituição não protege a sucessão em geral, mas apenas a herança em sentido estrito, ou seja, o direito de quem é herdeiro (e não o de quem é legatário); e, de outro lado, que a finalidade da norma constitucional é a proteção da sucessão legítima, cabendo à testamentária mera tutela infraconstitucional (inclusive quando disser respeito a herdeiros testamentários) ${ }^{16}$. Se tais argumentos prevalecerem, comprometida estará a nossa tese de que há implicitamente, no âmbito de proteção do referido dispositivo constitucional, o direito fundamental de testar.

$\mathrm{Na}$ verdade, precisamos tomar muito cuidado ao interpretar o direito de herança garantido entre os direitos fundamentais. Não devemos adotar a visão estreita de que o artigo $5^{\circ}, \mathrm{XXX}$ da Constituição Federal deve ser lido à luz da herança enquanto instituto positivado no Código Civil. Conforme Tiago Ensterseifter (2005, p.11) afirmou em contexto mais amplo, não podemos fazer a errada leitura no sentido código-constituição, em detrimento da adequada leitura no sentido constituição-código. Semelhantemente, Gustavo Tepedino (2008a, p.206) criticou a chamada "civilização do direito constitucional, que pretende indicar a suposta influência do direito civil e de suas categorias na interpretação constitucional". Gustavo Tepedino (2008b, p.363) também já ressaltou a necessidade de se evitar o "equívoco de entender o processo hermenêutico como uma via de mão dupla (influência recíproca entre normas constitucionais e normas de hierarquia inferior)", para impedir que sejam eternizadas "noções culturais ou consuetudinárias ultrapassadas, e reprovadas pela sociedade, contra a ordem pública constitucional, em favor de esquemas mentais misoneístas, construídos no passado e adotados de forma servil e acrítica pelo intérprete”. Para o referido autor, na medida em que a fundamentação hermenêutica é axiológica, e não lógica, "há de se manifestar necessariamente em um só sentido: são os valores constitucionais que devem impregnar cada

16 Paulo Lôbo fundamenta essa última afirmação na proteção constitucional às pessoas físicas que tenham relação de parentesco ou família com o de cujus, bem como em razão dos valores sociais e de solidariedade familiar. 
julgado, ou cada núcleo legislativo, ou cada categoria do direito infraconstitucional" (TEPEDINO, 2008b, p.364).

Devemos, então, interpretar o direito infraconstitucional como um todo, e o Livro do Direito das Sucessões do Código Civil de 2002 em especial, inclusive o instituto jurídico do testamento, à luz da Constituição (especificamente do direito fundamental à herança), e não o contrário. Nesse sentido, Pietro Perlingieri (2008, p.574) já sustentava que a norma constitucional é a justificação da norma ordinária, que por sua vez deve se harmonizar com coerência e razoabilidade àquela. Assim, a herança que encontramos na Constituição é que deve conformar a noção de herança (em sentido amplo, abarcando a sucessão testamentária) que está codificada.

Pelas razões acima expostas, discordamos do supramencionado entendimento de Paulo Lôbo. Acreditamos que o referido autor está indevidamente delimitando o conteúdo de um direito fundamental com base em uma distinção feita pelo legislador (e não pelo constituinte) ${ }^{17}$. Ainda que aceitássemos uma interpretação literal (e já excessivamente restritiva) do artigo $5^{\circ}, \mathrm{XXX}$ da Constituição Federal, no sentido de que há uma proteção à herança, mas não ao legado, não há qualquer fundamento para incluir no âmbito de proteção desse direito fundamental apenas a sucessão legítima e não a testamentária. Afinal, se a família (base da sucessão legítima) é objeto de tutela constitucional, a liberdade (autonomia privada - no caso, testamentária) também o é ${ }^{18}$.

Por outro lado, Paulo Lôbo (2017, p.150) ainda rejeita a proteção constitucional da sucessão testamentária afirmando que os valores sociais e de solidariedade familiar são mais bem contemplados na sucessão legítima, enquanto a sucessão testamentária privilegia excessivamente a autonomia individual. Não concordamos com a generalização feita pelo referido autor nem com a sua pressuposição de que a autonomia individual é necessariamente antissocial e realizadora de valores contrários aos estampados na Constituição.

Assim como Jeffrey P. Rosenfeld (1979, p.03), discordamos da tendência de rotular disposições testamentárias como intrinsecamente antissociais ou idiossincráticas. Rosenfeld

17 Cabe aqui a referência a Pietro Perlingieri (2002, p.74), para quem "a legalidade constitucional impõe uma interpretação da norma ordinária ou de grau inferior, à luz dos interesses e dos valores constitucionalmente relevantes, de maneira que limitar-se à letra clara ou ao sentido próprio das palavras (é possível?) ou à intenção do legislador, passado ou presente, significaria colocar-se fora desta legalidade (...)".

18 Sobre a proteção constitucional à autonomia privada, remetemos à clássica obra de Ana Prata (1987). 
critica a tradicional postura de se considerar que a sucessão em benefício da família sempre deve prevalecer em relação a obrigações para com terceiros; para este autor, esta crença obscurece as forças sociais que atuam quando alguém dispõe de patrimônio. Compreendemos que, com a liberdade de testar, o sujeito pode chamar à própria sucessão pessoas que dele dependiam e que seriam deixadas de lado pela rígida ordem de vocação hereditária prevista em lei, como por exemplo um irmão com deficiência ou um genitor idoso, que não serão beneficiados pela sucessão intestada caso o falecido tenha deixado descendentes. À luz dos valores constitucionais, a priori não há qualquer razão para censurar tais disposições testamentárias. A título ilustrativo, Daniel Monk (2011, p.231) relata que, antes de as legislações ou os tribunais reconhecerem a existência de direitos sucessórios legítimos nas relações entre pessoas do mesmo sexo, foi a liberdade de testar que permitiu que pessoas homossexuais beneficiassem seus parceiros.

Obviamente reconhecemos a possibilidade de a autonomia testamentária ser utilizada de forma abusiva. Identificar o direito de testar como fundamental não significa que ele seja absoluto, ilimitado. Mais à frente, refletiremos sobre alguns dos limites à liberdade de testar, que conformam o âmbito de proteção do referido direito aos demais valores e objetivos estampados na Constituição da República.

Conclusivamente, rejeitamos a ideia de que o âmbito de proteção do artigo $5^{\circ}$, XXX da Constituição Federal de 1988 se limita à sucessão legítima. Por todos os argumentos acima apresentados, concluímos que o direito fundamental de testar se encontra implicitamente protegido pela Constituição, enquanto desdobramento do direito fundamental à herança, titularizado pelo sucedido, entendido como uma liberdade e como uma competência. $\mathrm{O}$ reconhecimento desse caráter de fundamentalidade tem consequências, que brevemente analisaremos na seção seguinte.

\section{BREVE ANÁLISE SOBRE AS CONSEQUÊNCIAS DE SE RECONHECER UM DIREITO FUNDAMENTAL DE TESTAR}


As consequências de se reconhecer um direito como fundamental são inúmeras, em decorrência dos efeitos jurídicos que emanam das suas dimensões subjetiva e objetiva. Por limitação de espaço, faremos apenas breves considerações sobre alguns desses aspectos.

Em primeiro lugar, devemos notar que direitos fundamentais são direitos subjetivos oponíveis contra o Estado, mas também compõem uma ordem de valores fundamentais objetivos e são dotados de valia jurídica - no sentido de reconhecimento de efeitos jurídicos que transcendem a dimensão subjetiva (SARLET, 2015, p.151). Nesse sentido, a dimensão objetiva dos direitos fundamentais também se relaciona com a eficácia dirigente destes em relação aos órgãos estatais; eles contêm "uma ordem dirigida ao Estado no sentido de que a este incumbe a obrigação permanente de concretização e realização dos direitos fundamentais" (SARLET, 2015, p.152). Ademais, os direitos fundamentais são parâmetros orientadores para o controle de constitucionalidade.

Dessa forma, quando identificamos a existência de um direito fundamental de fazer testamento, induzimos que o Estado deve dirigir a sua atuação para permanentemente concretizar e realizar esse direito. Evidentemente, o primeiro passo para isso é estruturar um regime legal da sucessão testamentária; todavia, isso não é o bastante. O tratamento infraconstitucional da liberdade de testar deve ser compatível com: (a) os valores objetivos decorrentes deste direito fundamental; e (b) os limites impostos pela interação deste com outros direitos fundamentais.

Acreditamos então que a concretização e realização do direito fundamental de testar envolve o adequado tratamento infraconstitucional dado aos testamentos. Defendemos que isso demanda, em primeiro lugar, a diminuição formalidades testamentárias, de forma a facilitar acesso ao ato de dispor por testamento. Afinal, podemos considerar que o excesso de formalidades é um desestímulo ao ato de testar. Daí também decorre a necessidade de um menor rigor em relação a eventuais vícios formais; invalidar toda a manifestação de última vontade em razão da forma, por si só, é indevidamente dar prevalência ao invólucro, em detrimento da substância - a forma não é um fim em si mesma. Por fim, também entendemos como um aspecto garantidor dos interesses dos sucessores testamentários a existência do Registro Central de Testamentos On Line (RCTO), ligado à Central Notarial de Serviços Eletrônicos Compartilhados (CENSEC). Atualmente, o provimento 56/2016 da Corregedoria Nacional de Justiça, estabelece a obrigatoriedade de consulta ao RCTO, pelo juiz do 
inventário ou pelo tabelião responsável pelo inventário administrativo. Tal medida visa a diminuir a quantidade de testamentos que não são cumpridos por desconhecimento ou má-fé dos interessados, em prejuízo da eficácia concreta do direito fundamental de testar. Sustentamos que um importante passo seria a positivação do RCTO por meio de lei em sentido estrito.

Tendo o caráter de fundamental, o direito de testar serve como parâmetro de constitucionalidade do ordenamento infraconstitucional. Dessa forma, devemos reconhecer que ele tem eficácia tanto derrogatória quanto invalidante. Qualquer norma anterior à Constituição Federal de 1988 substancialmente incompatível com a liberdade de testar não foi recepcionada pelo texto constitucional, assim como será inválida qualquer norma posterior que viole o núcleo essencial do direito fundamental de fazer testamento. Isso obviamente não significa que se trate de um direito ilimitado, conforme observaremos na sequência.

Para além da composição de uma ordem objetiva de valores, a dimensão objetiva dos direitos fundamentais também se relaciona com a sua caracterização como um reforço ou complementação da eficácia normativa dessas normas - uma "mais-valia” jurídica (SARLET, 2015, p.153). De todo modo, podemos identificar cinco desdobramentos desta "mais-valia jurídica" dos direitos fundamentais, todos aplicáveis ao direito fundamental de fazer testamento: sua eficácia irradiante; sua eficácia na esfera privada; as garantias institucionais; dever geral de efetivação atribuído ao Estado; e a conformação e o procedimento da atividade estatal. Uma vez que há limite de páginas para o presente artigo, focaremos exclusivamente no aspecto das garantias institucionais, no sentido de "determinadas instituições (direito público) ou institutos (direito privado) que, por sua importância, devem estar protegidas contra a ação erosiva do legislador” (SARLET, 2015, p.154). Sendo assim, ao legislador ordinário é vedada a abolição da sucessão testamentária.

Em segundo lugar, devemos considerar os limites ao direito fundamental de fazer testamento; afinal, não se trata de um direito ilimitado e absoluto. De acordo com Gustavo Tepedino (2007, p.03), a autonomia privada é funcionalizada e tem seu valor social assegurado em razão da sua imprescindível submissão aos princípios constitucionais, que estão no vértice da hierarquia normativa. De igual modo, para Daniel Sarmento (2008, p.155), a autonomia privada não é absoluta e deve ser conciliada primeiramente com a autonomia privada alheia, bem como com outros valores constitucionais como a democracia, a 
igualdade, a solidariedade e a segurança. Por essa razão, os interesses patrimoniais não são protegidos como um fim em si mesmos, mas como meios de concretização da realização existencial da pessoa e de interesses socialmente relevantes (SARMENTO, 2008, p.179).

O direito de testar não é um fim em si mesmo. Com o fenômeno da constitucionalização do Direito Civil, a liberdade testamentária sofre uma alteração estrutural, passando por um juízo de compatibilidade com os princípios que conformam e orientam o nosso sistema normativo. Como Luiz Edson Fachin (2008, p,16) ensina, o Direito Civil brasileiro contemporâneo deve abandonar a noção de titularidades absolutas e também superar os debates que se restringem a abordar limites exógenos da propriedade e do contrato; o que se deve buscar é uma "teorização aprofundada dos limites internos, endógenos, a reclamar eficácia dos direitos fundamentais nas relações entre particulares".

Se testar é um direito fundamental, ele por vezes entra em tensões com direitos fundamentais de outras pessoas envolvidas na sucessão. Da ponderação dessas tensões, então, surgem restrições ao exercício da autonomia privada testamentária. Desse modo, a liberdade de testar tem fronteiras que a limitam, quantitativamente e qualitativamente, de modo a conformá-la à tábua axiológica da Constituição. Acreditamos que a promoção da solidariedade familiar é uma justificação constitucionalmente legítima para fundamentar a sucessão forçada, em benefício de determinados familiares do de cujus, enquanto restrição quantitativa ao direito de testar ${ }^{19}$. Por outro lado, aderimos ao pensamento de Ana Luiza Maia Nevares (2009, p.23), para quem deve haver uma análise qualitativa do conteúdo das disposições testamentárias à luz dos valores constitucionais. Nesse sentido, entendemos que condições abusivamente impostas no testamento, bem como cláusulas decorrentes de motivos ilícitos do testador, não são merecedoras de tutela, em relação aos princípios da Constituição. Lamentamos que o Código Civil de 2002 pouco tenha se debruçado sobre a matéria - que exige reflexões mais aprofundadas em espaço próprio.

Finalmente, em terceiro lugar, depreendemos que reconhecer o direito fundamental de testar significa lhe atribuir a qualidade de cláusula pétrea. De acordo com o artigo $60, \S 4^{\circ}$, IV do texto constitucional, eventuais emendas constitucionais tendentes a abolir os direitos e

19 Ressalvamos que, quando defendemos a constitucionalidade da sucessão forçada em benefício das pessoas próximas ao testador, não estamos necessariamente afirmando que o modelo adotado pelo Código Civil de 2002 - consistente na reserva rígida de 50\% do monte hereditário, independentemente da extensão do patrimônio sucessível, do número de sucessores e das efetivas circunstâncias individuais destes - seja o adequado para promover suficientemente os valores constitucionais. Contudo, o tema merece reflexão em espaço próprio. 
garantias individuais não serão objeto de deliberação. Essa vedação independe de o direito fundamental ser expresso ou implícito. Consequentemente, o direito a fazer testamento não pode ser suprimido do ordenamento jurídico brasileiro, nem mesmo por meio de uma emenda constitucional, enquanto vivermos sob a ordem da Constituição Federal de 1988.

\section{CONCLUSÃO}

$\mathrm{Na}$ presente investigação, observamos que não há no artigo $5^{\circ}$ da Constituição Federal um dispositivo que expressamente consagre a existência de um direito fundamental de fazer testamento. Entretanto, constatamos que isto não é um óbice ao reconhecimento de tal direito, na medida em que o texto constitucional admite que também há direito fundamentais implícitos.

Depreendemos que o direito fundamental de testar se encontra implicitamente abarcado pelo âmbito de proteção do artigo 5º XXX da Constituição Federal de 1988. Para chegarmos a tal conclusão, entendemos que deve prevalecer a tese da dupla titularidade do direito à herança, no sentido de que se trata de uma norma ambivalente, que tutela os interesses de duas ordens distintas de sujeitos: o sucedido, que tem o direito a deixar herança; e o sucessor, que tem o direito a receber herança.

Partindo da premissa acima, inferimos que o direito fundamental de fazer testamento é um desdobramento lógico do direito fundamental à herança, se observado da perspectiva dos interesses do sucedido. Nesse sentido, com base na doutrina de Robert Alexy, constatamos que, tomado em sua dimensão subjetiva, o direito fundamental à herança pode ser entendido como uma liberdade de ação juridicamente protegida - fazer ou não testamento. Semelhantemente, ainda na esteira do pensamento de Robert Alexy, averiguamos que ainda em sua dimensão subjetiva, o direito fundamental à herança pode ser compreendido como uma competência do testador, no sentido de que este tem o poder jurídico de, dentro de certos limites, alterar as situações jurídicas dos sucessores.

Por outro lado, deduzimos que não procedem as alegações de que somente a sucessão legítima é tutelada pelo artigo $5^{\circ}, \mathrm{XXX}$ da Constituição Federal. Advertimos que tal entendimento configuraria uma interpretação da norma constitucional à luz da lei ordinária, 
enquanto a metodologia civil-constitucional exige uma interpretação em direção contrária, qual seja, no sentido constituição-código. Induzimos ainda que, na delimitação do âmbito de proteção de um direito fundamental, não são cabíveis restrições interpretativas baseadas exclusivamente em divisões feitas pelo legislador ordinário (e não pelo constituinte).

Por fim, concluímos que, do caráter de fundamentalidade do direito de fazer testamento, decorrem diversas consequências jurídicas. Demos especial destaque a três. Em primeiro lugar, a liberdade de testar, além de ser oponível contra o Estado, ingressa na ordem de valores fundamentais do nosso ordenamento, pautando a interpretação do direito objetivo e atuação dos poderes públicos. Daí a impossibilidade de sua abolição por ato do legislador ordinário. Em segundo lugar, reconhecemos que a liberdade de testar não é absoluta e ilimitada, podendo sofrer restrições quantitativas e qualitativas em decorrência de sua concorrência com outros valores constitucionalmente tutelados. Por último, depreendemos que o direito de fazer testamento se reveste da proteção às cláusulas pétreas, não podendo ser abolido sequer por Emenda Constitucional.

\section{REFERÊNCIAS}

ALEXY, Robert. Teoria dos direitos fundamentais. $2^{\mathrm{a}}$ edição, $4^{\mathrm{a}}$ tiragem. Tradução da $5^{\mathrm{a}}$ edição alemã (2006) por Virgílio Afonso da Silva. São Paulo: Malheiros, 2015.

ANDRADE, José Carlos Vieira de. Os direitos fundamentais na Constituição portuguesa de 1976. $2^{a}$ ed. Coimbra, PT: Almedina, 2001.

ASCHER, Mark L. Curtailing inherited wealth. Michigan Law Review, n. 89, 1990.

ENSTERSEIFTER, Tiago. A Função Social Como Elemento Constitutivo Do Núcleo Normativo-Axiológico Do Direito De (À) Propriedade Uma Leitura Comprometida Com A Realidade Social Brasileira. Revista da Faculdade de Direito UFPR, Curitiba, PR, Brasil, dez. 2005. ISSN 2236-7284. Disponível em: https://revistas.ufpr.br/direito/article/view/7059. Acesso em: 17 jul. 2018.

FACHIN, Luiz Edson. A construção do Direito Privado Contemporâneo na experiência crítico-doutrinária brasileira a partir do catálogo mínimo para o Direito Civil-Constitucional no Brasil. In: TEPEDINO, Gustavo (org.). Direito civil contemporâneo: novos problemas à luz da legalidade constitucional: anais do Congresso Internacional de Direito CivilConstitucional da Cidade do Rio de Janeiro. São Paulo: Atlas, 2008. 
GOMES, Felipe Lima. O direito fundamental à herança: âmbito de proteção e consequências de sua constitucionalização. Tese (Doutorado) - Universidade Federal do Ceará, Faculdade de Direito, Programa de Pós-Graduação em Direito, Fortaleza, 2015.

GROTIUS, Hugo. On the law of war and peace. Edited by Stephen C. Neff. Cambridge, UK: Cambridge University Press, 2012.

KREICZER-LEVY, Shelly. Inheritance legal systems and the intergerational bond. Real Property, Trust and Estate Law Journal, vol.46, n.3, 2012.

LEITE, Eduardo de Oliveira. Comentários ao Novo Código Civil, volume XXI: do direito das sucessões: arts. 1.784 a 2.027. Rio de Janeiro: Forense, 2003.

LÔBO, Paulo. Direito civil: sucessões. 2. Ed. São Paulo: Saraiva, 2014.

LÔBO, Paulo. Saisine e liberdade de testar: a experiência brasileira. Revista Brasileira de Direito Comparado, Rio de Janeiro, n.48, 2017.

MAXIMILIANO, Carlos. Direito das sucessões, v. I. $5^{\text {a }}$ ed. - Rio de Janeiro: Freitas Bastos, 1964.

MIRAGLIA, Luigi. Filosofia del derecho. Buenos Aires, AR: Impulso, 1943.

MONK, Daniel. Sexuality and succession law: beyond formal equality. Feminist Legal Studies, vol.19, 2011.

MURPHY, Liam; NAGEL, Thomas. The Myth of Ownership: Taxes and Justice. Oxford, England: Oxford Scholarship Online, 2003.

NEVARES, Ana Luiza Maia. A função promocional do testamento - tendências do direito sucessório. Rio de Janeiro: Renovar, 2009.

OLIVEIRA, Arthur Vasco Itabaiana de. Tratado de direito das successões: exposição doutrinaria do Livro IV da parte especial do Codigo civil brasileiro (Lei n. 3.071 de 1 de janeiro de 1916), vol. I. 3. ed. rev. e aum. Rio de Janeiro, RJ: Jacintho Ribeiro dos Santos, 1936.

PERLINGIERI, Pietro. Perfis do Direito Civil: Introdução ao Direito Civil

Constitucional. Tradução de Maria Cristina de Cicco. $2^{\mathrm{a}}$ ed. - Rio de Janeiro: Renovar, 2002.

PERLINGIERI, Pietro. O direito civil na legalidade constitucional. Tradução de Maria Cristina De Cicco. Rio de Janeiro: Renovar, 2008.

PONTES DE MIRANDA, Francisco Cavalcanti. Tratado dos testamentos, v. I. Leme: BH Editora e Distribuidora, 2005.

PRATA, Ana. A tutela constitucional da autonomia privada. Coimbra: Almedina, 1982. 
PUFENDORF, Samuel. Of the law of nature and nations, eight books. Translated by Basil Kennett and William Percivale. Oxford: L. Lichfield, 1703.

RIBEIRO, Raphael Rego Borges. Hugo Grotius and Samuel Pufendorf on Last Wills and Testaments. Grotiana, vol. 40, 2019.

ROSENFELD, Jeffrey P. The legacy of aging: inheritance and disinheritance in social perspective. Norwood: Ablex Publishing Corporation, 1979.

SARLET, Ingo Wolfgang. A eficácia dos direitos fundamentais: uma teoria geral dos direitos fundamentais na perspectiva constitucional. 12. ed. rev. atual e ampl. Porto Alegre: Livraria do Advogado Editora, 2015.

SARMENTO, Daniel. Direitos fundamentais e relações privadas. $-2^{\mathrm{a}}$ edição, $2^{\mathrm{a}}$ tiragem. Rio de Janeiro: Lumen Juris, 2008.

TEPEDINO, Gustavo. Normas constitucionais e direito civil na construção unitária do ordenamento. 2007. Disponível em: https://www12.senado.leg.br/publicacoes/estudoslegislativos/tipos-de-estudos/outras-publicacoes/volume-iii-constituicao-de-1988-o-brasil-20anos-depois.-a-consolidacao-das-instituicoes/hermeneutica-constitucional-e-sumulavinculante-normas-constitucionais-e-direito-civil-na-construcao-unitaria-do-ordenamento. Acesso em 07 de junho de 2018.

TEPEDINO, Gustavo. Normas constitucionais e relações privadas na experiência das Cortes Superiores brasileiras. Boletim científico - Escola Superior do Ministério Público da União, Brasília, ano 7, n.28/29, jul/dez. 2008.

TEPEDINO, Gustavo. O direito civil-constitucional e suas perspectivas atuais. In: TEPEDINO, Gustavo (org.). Direito civil contemporâneo: novos problemas à luz da legalidade constitucional: anais do Congresso Internacional de Direito CivilConstitucional da Cidade do Rio de Janeiro. São Paulo: Atlas, 2008.

TRITT, Lee-ford. Technical Correction or Tectonic Shift: competing default rule theory under the new Uniform Probate Code. Alabama Law Review, vol. 61, n. 2, 2010.

VELOSO, Zeno. Testamentos - noções gerais; formas ordinárias; codicilo; formas especiais. In: HIRONAKA, Giselda Maria Fernandes Novaes; PEREIRA, Rodrigo da Cunha (coord). Direito das sucessões e o novo código civil. Belo Horizonte: Del Rey, 2004.

WIEACKER, Franz. História do Direito Privado Moderno. 2 ed. trad. por A. M. Hespanha. Lisboa: Fundação Calouste Gulbenkian, 1967. 